\title{
Atividade de peroxidase e polifenoloxidase na resistência do feijão à antracnose
}

\author{
Ângela Diniz Campos ${ }^{(1)}$, Alfredo Gui Ferreira(2), Magdolna Maria Vozarí Hampe ${ }^{(2)}$, Irajá Ferreira Antunes ${ }^{(1)}$, \\ Nely Brancão(1), Expedito Paulo da Silveira(1), Vera Allgayer Osório(1) e Eliane Augustin ${ }^{(1)}$
}

\begin{abstract}
(1)Embrapa Clima Temperado, Caixa Postal 403, CEP 96001-970 Pelotas, RS. E-mail: angela@cpact.embrapa.br (2)Universidade Federal do Rio Grande do Sul, Instituto de Biociências, Dep. de Botânica, Av. Paulo Gomes s/no, CEP 91509-900 Porto Alegre, RS. E-mail: ferreira@unb.br, hampe@orion.ufrgs.br
\end{abstract}

Resumo - O objetivo deste trabalho foi avaliar a influência das enzimas peroxidase e polifenoloxidase na resistência à antracnose de quatro cultivares de feijão. Plântulas de feijão foram pulverizadas com ácido salicílico e com a raça delta de Colletotrichum lindemuthianum (fungo indutor) e submetidas à inoculação do patótipo virulento 33/95 de C. lindemuthianum três dias após a aplicação do fungo indutor e do ácido salicílico. Essas plantas foram avaliadas quanto à atividade enzimática e teores de fenóis, três dias após a aplicação do fungo indutor e cinco dias após a inoculação do patótipo virulento. Acréscimos nas atividades dessas enzimas foram maiores nos tratamentos com ácido salicílico e fungo indutor em todas as cultivares. Maiores estímulos nas atividades enzimáticas foram observados nas cultivares com maior resistência à doença. Constatou-se o aparecimento de uma isoperoxidase nos tratamentos com fungo indutor, ácido salicílico, após inoculação do patótipo virulento, e na testemunha, nas cultivares AB 136, Rio Tibagi e Macanudo. Houve correlação positiva entre as atividades da peroxidase e da polifenoloxidase, os teores de compostos fenólicos e a resistência à antracnose.

Termos para indexação: Phaseolus vulgaris, Colletotrichum lindemuthianum, resistência sistêmica adquirida.

\section{Peroxidase and polyphenol oxidase activity in bean anthracnose resistance}

\begin{abstract}
The objective of this work was to evaluate the influence of peroxidase and polyphenol oxidase enzymes in anthracnose resistance of four bean cultivars. Seedlings were sprinkled with salicylic acid and delta race of Colletotrichum lindemuthianum (inducer fungus) and after three days they were inoculated with 33/95 virulent pathotype of $C$. lindemuthianum. Enzyme activity and phenol levels were evaluated three days after inducer fungus application and five days after inoculation with virulent pathotype. Plants treated with salicylic acid and inducer fungus presented higher activity increases of both enzymes, in all cultivars. Higher impulses in enzymatic activity were observed in cultivars with higher disease resistance. One isoperoxidase appeared in treatments with inducer fungus, salicylic acid, after inoculation with virulent pathotype, and in control plants, in AB 136, Rio Tibagi and Macanudo cultivars. Positive correlation was observed among peroxidase and polyphenol oxidase activity, phenolic compound levels and anthracnose resistance.
\end{abstract}

Index terms: Phaseolus vulgaris, Colletotrichum lindemuthianum, acquired systemic resistance.

\section{Introdução}

O emprego da resistência genética, no sistema integrado de controle visando à redução de perdas ocasionadas por doenças, tem merecido destaque (Agrios, 1997). Compostos fenólicos, que são produzidos rapidamente e se acumulam após a infecção, especialmente em variedades resistentes, são tóxicos aos patógenos. Os ácidos clorogênico, caféico e ferrúlico são exemplos de alguns desses compostos.
Algumas formas de fenóis podem ser convertidas em derivados com radicais de oxigênio, extremamente reativos, tornando-se muito tóxicos (Hartleb et al., 1997). Os fenóis possuem, pelo menos, um anel benzênico, com um ou mais grupos hidroxila, livres ou substituídos. A biossíntese do anel benzênico é um dos processos fundamentais da biologia, com significância fisiológica, genética, fitoquímica e ecológica para a planta (Piñol \& Palazón, 1996). 
A peroxidase é uma importante enzima das plantas e está envolvida em diversas reações, ligações de polissacarídeos, oxidação do ácido indol-3-acético, ligações de monômeros, lignificação, cicatrização de ferimentos, oxidação de fenóis, defesa de patógenos, regulação da elongação de células e outras (Gaspar et al., 1982; Kao, 2003).

A polifenoloxidase geralmente é elevada em tecidos infectados e tem grande importância para as plantas, com envolvimento nos mecanismos de defesa ou na senescência (Agrios, 1997).

Peroxidases e polifenoloxidases lideram a degradação oxidativa de compostos fenólicos próximo ao local da descompartimentalização celular provocada por patógenos. Um dos resultados mais estudados deste fenômeno é o aparecimento de substâncias escuras provenientes da polimerização oxidativa das quinonas (Macheix et al., 1986; Bindschedler et al., 2002). Somente o primeiro estádio da infecção permite a formação de quinonas a partir de o-difenóis pelo processo enzimático (Mason, 1955; Zheng-Cuiming et al., 1999). No entanto, há uma sequiência de reações químicas que são ainda pouco conhecidas.

A rápida intervenção da peroxidase na lesão provocada por fungo também resulta no aparecimento do fenômeno de quimiluminescência, que tem sido observado em tecidos doentes de raízes (Salin \& Bridges, 1981). Esta não deve ser causada por uma nova síntese de peroxidase, mas provavelmente é resultante do escurecimento proveniente da ação da enzima nos substratos, que podem ser tanto fenóis (Slawinska, 1978) como outros tipos de compostos, tais como ácido indolacético (Salin \& Bridges, 1983). Outra possível rota para a modificação de fenóis solúveis é a associação com macromoléculas presentes no local da lesão, especialmente proteínas (Synge, 1980, citado por Macheix et al., 1986).

Em muitas doenças, essas modificações metabólicas foram demonstradas como fator promotor da inibição do crescimento do patógeno. Compostos produzidos pela planta, durante o processo de doença, têm desempenhado um papel crucial na resistência ao organismo invasor (Cruickshank \& Perrin, 1963; Nandakumar et al., 2001; Bindschedler et al., 2002). O composto fenólico mais bem caracterizado em feijão é a faseolina, produzida quando as plantas de Phaseolus vulgaris são atacadas por fungos (Rahe et al., 1969).

A ativação das formas latentes de peroxidase, após a destruição ou inativação de inibidores protéicos ou fenólicos, pode conduzir à indução de síntese de isoformas de peroxidase (Birecka et al., 1973).
O objetivo deste trabalho foi avaliar a influência das enzimas peroxidase, polifenoloxidase e de compostos fenólicos na resistência à antracnose de quatro cultivares de feijão.

\section{Material e Métodos}

Este trabalho foi realizado na Embrapa Clima Temperado e na Universidade Federal do Rio Grande do Sul (UFRGS). Foram avaliadas as cultivares de feijão (Phaseolus vulgaris L.) AB 136, Carioca, Macanudo e Rio Tibagi, no estádio de plântulas. O delineamento experimental foi o inteiramente casualizado, do fatorial cultivares x tratamentos, em cinco repetições, com parcelas subdivididas. As análises de variância e os cálculos do coeficiente de correlação foram realizados segundo Zonta \& Machado (1984).

As sementes foram semeadas em bandejas de plástico $(55 \times 40 \times 15 \mathrm{~cm})$ contendo areia esterilizada, e irrigadas com solução nutritiva completa (Smith et al., 1963). Nove dias após a germinação, realizou-se aspersão com atomizador manual, nas folhas, com as preparações de Colletotrichum lindemuthianum raça delta (fungo indutor na concentração de $1,4 \times 10^{6}$ esporos por $\mathrm{mL}$ ), ácido salicílico $(0,01 \mathrm{M})$ e água. Após três dias, realizaram-se coletas para as análises bioquímicas e em seguida as plantas foram aspergidas com o patótipo virulento de $C$. lindemuthianum, isolado 33/95, proveniente do Rio Grande do Sul, na concentração de 2,27x $10^{4}$ esporos por $\mathrm{mL}$. Cinco dias após, realizaram-se novas coletas para as análises bioquímicas e avaliação da incidência da doença. A seguir, as plantas foram mantidas em condições ideais para o crescimento do fungo, ou seja, temperatura de $22 \pm 2^{\circ} \mathrm{C}$ e umidade relativa de $95 \%$, com iluminação mista de aproximadamente $195 \mu \mathrm{E} \mathrm{s}^{-1} \mathrm{~m}^{-2}$, por 14 horas. Na produção dos inóculos, foi utilizado o meio de Mathur et al. (1950).

Os tecidos foram pesados, rapidamente congelados em gelo seco e armazenados a $80^{\circ} \mathrm{C}$ negativos, para análises posteriores. As folhas congeladas foram homogeneizadas à temperatura máxima de $4^{\circ} \mathrm{C}$ em $10 \mathrm{~mL}$ de tampão fosfato $0,05 \mathrm{M}(\mathrm{pH} \mathrm{7,0)}$, contendo $1 \mathrm{mg}$ de polivinilpirrolidona-10. $\mathrm{O}$ homogeneizado foi filtrado, centrifugado a $4.000 \mathrm{~g}$ por 20 minutos, sob refrigeração, e o precipitado foi descartado. O sobrenadante foi conservado em gelo e usado nas determinações de peroxidase e polifenoloxidase.

A atividade da polifenoloxidase foi determinada de acordo com a técnica descrita por Hyodo \& Yang (1971), 
com as modificações descritas a seguir. Em tubo gelado, foram colocados $3,6 \mathrm{~mL}$ de tampão fosfato $0,05 \mathrm{M}$, $\mathrm{pH} 6,0,1 \mathrm{~mL}$ do extrato enzimático, $0,1 \mathrm{~mL}$ de catecol $0,1 \mathrm{M}$, e a mistura foi agitada em vortex por 15 segundos. O tubo com a mistura foi incubado a $30^{\circ} \mathrm{C}$ por 30 minutos e transferido para um banho de gelo. À mistura foi adicionado $0,2 \mathrm{~mL}$ de ácido perclórico a 1,4\% e, após agitação em vortex, o tubo foi deixado em repouso por 10 minutos. A absorvância foi lida a $395 \mathrm{~nm}$ em espectrofotômetro. No controle, o extrato enzimático foi substituído por água. A atividade da enzima foi expressa em unidade enzimática (UE). Uma unidade da enzima foi definida como a quantidade de enzima que causou um aumento de 0,001 unidade de absorvância por minuto.

A atividade da peroxidase foi determinada de acordo com a técnica descrita por Matsuno \& Uritani (1972), com as seguintes modificações. Em tubo gelado foram colocados $2,5 \mathrm{~mL}$ de tampão fosfato-citrato contendo solução de fosfato de sódio dibásico $0,2 \mathrm{M}$ e ácido cítrico $0,1 \mathrm{M}, \mathrm{pH} 5,0,1,5 \mathrm{~mL}$ de extrato enzimático e $0,25 \mathrm{~mL}$ de guaiacol $0,5 \%$, sendo a mistura agitada em vortex durante 15 segundos. Em seguida, $0,25 \mathrm{~mL}$ de $\mathrm{H}_{2} \mathrm{O}_{2} 3 \%$ foi adicionado e a mistura novamente agitada em vortex. A mistura foi incubada a $30^{\circ} \mathrm{C}$ por 15 minutos e transferida para um banho de gelo; à mistura foi adicionado $0,25 \mathrm{~mL}$ da solução de metabissulfito de sódio a $2 \%$. Após agitação em vortex, a mistura foi deixada em repouso por 10 minutos. A absorvância foi lida a $450 \mathrm{~nm}$, em espectrofotômetro. No controle, o extrato enzimático foi substituído por água. A atividade da enzima foi expressa em unidade enzimática (UE). Uma unidade da enzima foi definida como a quantidade de extrato enzimático que acusou um aumento na absorvância de 0,001 unidade por minuto. A concentração de proteína foi analisada pelo método de Lowry et al. (1951).
As isoperoxidases foram determinadas em amostras coletadas cinco dias após as inoculações com o patótipo virulento de $C$. lindemuthianum. Foi utilizada a eletroforese horizontal em gel de poliacrilamida $5 \%$ na avaliação das isoenzimas de peroxidase em folhas de feijão, no sistema descontínuo de tampões descrito por Scandalios (1969). Na preparação do extrato para as análises, utilizou-se uma parte da amostra e igual volume da mistura (1 parte do tampão lítio-borato $0,2 \mathrm{M}$, pH 8,3 e 9 partes do tampão tris-cítrico $0,2 \mathrm{M}, \mathrm{pH} 8,3$ ), acrescida de 2-mercaptoetanol 0,15\%. A migração eletroforética efetuou-se em câmara fria mantida a uma temperatura de $4^{\circ} \mathrm{C}$. A diferença de potencial foi mantida ao redor de 10 volts $^{-1} \mathrm{~cm}$, fazendo-se migrar até que o fronte, formado pelos tampões e marcado pelo azul de bromofenol, atingisse $9 \mathrm{~cm}$ a partir do ponto de aplicação das amostras. O gel foi corado com guaiacol para visualização das isoenzimas de peroxidase.

Os compostos fenólicos foram extraídos da matéria seca das folhas, conforme Swain \& Hillis (1959), e identificados segundo Folin Denis, citado pela Association of Official Analytical Chemists (1970) e Kosuge (1969).

\section{Resultados e Discussão}

Antes da inoculação do patótipo virulento, a atividade da polifenoloxidase foi maior nos tratamentos com ácido salicílico e $C$. Lindemuthianum, com significativos acréscimos, quando comparados com os resultados do controle, indicando uma indução na atividade destas enzimas (Tabela 1). Após a inoculação do patótipo virulento, a cultivar $\mathrm{AB} 136$ não diferiu nos tratamentos com ácido salicílico, fungo indutor e patótipo virulento, apresentando rápida resposta ao ataque do fungo virulento. Esta cultivar, considerada resistente, apresentou maior

Tabela 1. Atividade da peroxidase (UE $\mathrm{min}^{-1} \mathrm{mg}^{-1}$ tecido) em quatro cultivares de feijão, no estádio de plântula (V2), três dias após tratamento com a raça delta de Colletotrichum lindemuthianum (fungo indutor), ácido salicílico e água (controle), e cinco dias após inoculação do patótipo virulento (33/95) de C. lindemuthianum (inóculo desafio) ${ }^{(1)}$.

\begin{tabular}{|c|c|c|c|c|c|c|c|c|}
\hline \multirow[t]{2}{*}{ Tratamento } & \multicolumn{4}{|c|}{ Três dias após indução } & \multicolumn{4}{|c|}{ Cinco dias após inóculo desafio } \\
\hline & AB 136 & Rio Tibagi & Carioca & Macanudo & AB 136 & Rio Tibagi & Carioca & Macanudo \\
\hline Ácido salicílico & $72,0 \mathrm{aA}$ & $50,3 \mathrm{aC}$ & $35,0 \mathrm{aD}$ & $56,3 \mathrm{aB}$ & $75,4 \mathrm{aA}$ & $57,7 \mathrm{aC}$ & $27,3 \mathrm{bD}$ & $75,3 \mathrm{aB}$ \\
\hline C. lindemuthianum & $67,7 \mathrm{bA}$ & $46,0 \mathrm{bB}$ & $30,3 \mathrm{bC}$ & $44,7 \mathrm{bB}$ & $72,7 \mathrm{aA}$ & $52,7 \mathrm{bC}$ & $23,7 \mathrm{cD}$ & $73,0 \mathrm{aB}$ \\
\hline Controle & $31,7 \mathrm{cA}$ & $27,3 \mathrm{cC}$ & $26,0 \mathrm{cC}$ & $28,3 \mathrm{cB}$ & $39,0 \mathrm{bA}$ & $30,3 \mathrm{~dB}$ & $29,3 \mathrm{aC}$ & $39,3 \mathrm{dA}$ \\
\hline Patótipo virulento ${ }^{(2)}$ & $31,0 \mathrm{cA}$ & $26,7 \mathrm{cC}$ & $25,7 \mathrm{cC}$ & $28,7 \mathrm{cB}$ & $74,3 \mathrm{aA}$ & $50,0 \mathrm{cC}$ & $11,7 \mathrm{dD}$ & $70,7 \mathrm{aB}$ \\
\hline
\end{tabular}

${ }^{(1)}$ Médias seguidas pelas mesmas letras, minúsculas nas colunas e maiúsculas nas linhas, não diferem entre si pelo teste de Duncan a $5 \%$ de probabilidade. ${ }^{(2)}$ Antes da inoculação do patótipo virulento, as médias apresentadas representam tratamento com água. 
atividade da enzima após indução aos três dias, em todos os tratamentos, seguida pela Macanudo. A cultivar Carioca, considerada suscetível, apresentou menor atividade de polifenoloxidase em todos os tratamentos, até mesmo no tratamento com água.

Quanto aos compostos fenólicos, as formas extraídas em metanol $100 \%$ e metanol $50 \%$ apresentaram maiores concentrações, exceto os teores em metanol $50 \%$ da cultivar Carioca (Tabela 2). Os teores de fenólicos extraíveis em água foram superiores nos tratamentos com ácido salicílico e $C$. lindemuthianum nas cultivares AB 136, Macanudo e Rio Tibagi.

O maior acúmulo de compostos fenólicos ocorreu na cultivar AB 136, quando tratada com ácido salicílico e com o patótipo virulento (Tabela 2). Esta cultivar não apresentou nenhuma lesão. O acúmulo de compostos fenólicos variou de acordo com a cultivar. Estes dados são consistentes com as afirmações de Macheix et al. (1986), de que há uma distinção entre cultivares e estádios de desenvolvimento das plantas no acúmulo de compostos fenólicos e a resposta aos ferimentos. A ativação do metabolismo de fenóis após uma infecção, segundo esses autores, pode levar mais ou menos tempo, dependendo da formação de moléculas mais simples e de sua integração com estruturas químicas mais complexas,

Tabela 2. Teor de compostos fenólicos (mg $100 \mathrm{~g}^{-1}$ ), extraídos em metanol e água, de folhas de feijão no estádio de plântula, após tratamento de indução com Colletotrichum lindemuthianum (fungo indutor), ácido salicílico e água (controle), cinco dias após inoculação do patótipo virulento de C. lindemuthianum ${ }^{(1)}$.

\begin{tabular}{llcll}
\hline Tratamento & \multicolumn{4}{c}{ Cultivar } \\
\cline { 2 - 6 } & AB 136 & Rio Tibagi Carioca & Macanudo \\
\hline C. lindemuthianum & $1,16 \mathrm{cA}$ & $1,11 \mathrm{cB}$ & $0,99 \mathrm{dC}$ & $1,14 \mathrm{cAB}$ \\
Ácido salicílico & $1,26 \mathrm{bA}$ & $1,18 \mathrm{bB}$ & $1,13 \mathrm{bC}$ & $1,20 \mathrm{bB}$ \\
Controle & $1,11 \mathrm{dA}$ & $1,07 \mathrm{cB}$ & $1,10 \mathrm{cAB}$ & $1,13 \mathrm{cA}$ \\
Patótipo virulento & $1,35 \mathrm{aA}$ & $1,31 \mathrm{aB}$ & $1,16 \mathrm{aC}$ & $1,33 \mathrm{aAB}$ \\
\hline & \multicolumn{5}{c}{ Metanol $50 \%$} \\
C. lindemuthianum & $1,32 \mathrm{~dB}$ & $1,35 \mathrm{cB}$ & $1,34 \mathrm{cB}$ & $1,38 \mathrm{cA}$ \\
Ácido salicílico & $1,63 \mathrm{bA}$ & $1,45 \mathrm{bD}$ & $1,51 \mathrm{aC}$ & $1,54 \mathrm{bB}$ \\
Controle & $1,53 \mathrm{cA}$ & $1,34 \mathrm{cC}$ & $1,40 \mathrm{bD}$ & $1,36 \mathrm{dC}$ \\
Patótipo virulento & $1,67 \mathrm{aA}$ & $1,60 \mathrm{aB}$ & $0,90 \mathrm{dC}$ & $1,67 \mathrm{aA}$ \\
\hline & & \multicolumn{5}{c}{ Água } \\
C. lindemuthianum & $0,88 \mathrm{bA}$ & $0,65 \mathrm{cB}$ & $0,53 \mathrm{dC}$ & $0,68 \mathrm{cB}$ \\
Ácido salicílico & $0,94 \mathrm{aA}$ & $0,71 \mathrm{cC}$ & $0,65 \mathrm{bD}$ & $0,74 \mathrm{bB}$ \\
Controle & $0,76 \mathrm{cAB}$ & $0,74 \mathrm{bB}$ & $0,78 \mathrm{aA}$ & $0,76 \mathrm{bAB}$ \\
Patótipo virulento & $0,86 \mathrm{bA}$ & $0,77 \mathrm{aC}$ & $0,61 \mathrm{cD}$ & $0,80 \mathrm{aB}$ \\
\hline
\end{tabular}

\footnotetext{
${ }^{(1)}$ Médias seguidas pelas mesmas letras, maiúsculas nas linhas e minúsculas nas colunas, não diferem entre si pelo teste de Duncan a $5 \%$ de probabilidade.
}

semelhantes a ligninas. Este fenômeno, de acordo com Bell (1981), pode ser interpretado como parte da indução de resistência de uma planta.

A análise da correlação entre atividade da polifenoloxidase e fenóis extraíveis em metanol $50 \%$ foi estatisticamente significativa $(R=0,7800)$, assim como a correlação entre fenóis extraíveis em água e atividade da polifenoloxidase $(\mathrm{R}=0,9345)$ e da peroxidase $(\mathrm{R}=0,9042)$, em todos os tratamentos. Estes resultados podem ser atribuídos à oxidação desses polímeros pela ação dessas enzimas, após o estímulo de indução da resistência pelo fungo indutor ou pelo ácido salicílico, sendo, com isto, dificultada a penetração do patógeno.

Os teores mais elevados de fenólicos extraíveis em metanol $50 \%$ podem ter sido conseqüência da ação da polifenoloxidase na hidroxilação de monofenóis e oxidação de difenóis. Segundo Wheatley (1982), a ação da polifenoloxidase processa-se por meio da hidroxilação de monofenóis para o-difenóis e oxidação destes o-difenóis para quinonas. Conforme Padmaja et al. (1982), os fenóis já presentes no ferimento de raízes de mandioca são oxidados para o-quinonas ou polímeros pela ação da polifenoloxidase, havendo estímulo à biossíntese de oxidação destes fenóis e conseqüentemente, um aumento da atividade desta enzima.

As quinonas presentes nos ferimentos têm ação antimicrobiana e os polímeros podem atuar como taninos, formando complexos com proteínas que atuam como barreira física na penetração de patógenos (Mueller \& Beckman, 1974). Cardoso \& Garraway (1977) demonstraram que as substâncias provenientes do material castanho da lesão de hipocótilos doentes de feijoeiros inibiam seletivamente isolados não-patogênicos ao feijoeiro. A cultivar AB 136, considerada como altamente resistente ao $C$. lindemuthianum, seguida pela cultivar Macanudo, apresentaram maior atividade de polifenoloxidase, enquanto a cultivar suscetível Carioca apresentou menor atividade desta enzima (Tabela 1). Agrios (1997) e Orober et al. (1999) também constataram que geralmente ocorre maior atividade da polifenoloxidase nos tecidos infectados de cultivares resistentes do que em tecidos infectados de cultivares suscetíveis ou em plantas sadias. A importância da atividade da polifenoloxidase na resistência a doenças, deve-se, provavelmente, à sua propriedade em oxidar compostos fenólicos para quinonas, os quais são muito mais tóxicos aos microrganismos do que o fenol original, e à sua ação protetora no local do ferimento. 
Por esta razão, admite-se que um aumento na atividade da polifenoloxidase resulta em altas concentrações de produtos tóxicos de oxidação e, portanto, maior grau de resistência à infecção (Agrios, 1997; Zheng-Cuiming et al., 1999).

A atividade da peroxidase foi significativamente maior nas plantas tratadas com ácido salicílico e com o fungo indutor, antes e após a inoculação do patótipo virulento (Tabela 3). A cultivar AB 136 apresentou maior atividade desta enzima seguida pela Macanudo.

O estímulo na indução da atividade desta enzima, uma vez desencadeado pelo fungo indutor ou ácido salicílico, permaneceu após tratamento com o patótipo virulento. A cultivar Carioca, por ser suscetível, apresentava, aos cinco dias após a inoculação, grandes lesões provocadas pelo patótipo virulento. O metabolismo dos polifenóis, em determinadas situações, pode atuar como antioxidante e inativar o centro ativo de numerosas enzimas fenolases, incluindo a peroxidase (Piñol \& Palazón, 1996). Por sua vez, a biossíntese de compostos secundários depende da constituição genética da planta, que determina a formação das enzimas de especialização correspondentes.

Marriott et al. (1978) constataram que aumentos na atividade da peroxidase, associados com ferimentos em vegetais, podem indicar aumento na biossíntese de lignina, que atua como uma barreira à infecção microbiana e também pode promover aumentos na concentração de produtos de oxidação de fenólicos, alterando a concentração de auxinas por causa da presença de AIAoxidase. Birecka \& Garraway (1978) também observaram aumentos na atividade da peroxidase em ferimentos ou tecidos infectados, perceptíveis 24 horas após o ferimento e continuando por muitos dias. Alguns trabalhos descrevem que o aumento na atividade da peroxidase é parte da fase geral de ativação do metabolismo, que sintetiza de novo esta enzima (Kanazawa et al., 1965; Fleuriet \& Deloire, 1982). Esta reação ocorre rapidamente nas células infectadas, com estímulo do metabolismo das células vizinhas, organizando e estabelecendo um efetivo sistema de defesa pela planta em direção à área do ferimento. Em geral, as células mais próximas da área do ferimento são envolvidas (Fleuriet \& Deloire, 1982). No entanto, a existência de um sinal sistêmico originado na zona de ferimento foi demonstrada por Walker-Simmons et al. (1984). Uma nova expressão do genoma também foi observada (Kahl, 1978), e estes novos transcriptomas (Souza et al., 2001) correspondem à síntese de novo de novas enzimas, incluindo peroxidase e várias outras enzimas do metabolismo de fenóis, aumentando, deste modo, o arsenal de proteoma.

Nos eletroferogramas dos extratos enzimáticos analisados para peroxidase, observa-se tanto nos tratamentos de indução de resistência, quanto no tratamento com o patótipo virulento, o aparecimento de uma nova banda protéica com atividade peroxidásica, perto da linha de frente do gel (Figura 1). Essa banda, que corresponde a uma isoperoxidase, não aparece nas plantas sadias ou sem estímulo de indução, nem nas análises de extratos enzimáticos das folhas da cultivar Carioca, considerada suscetível. Observa-se, também, a presença de bandas ativas na região anódica dos géis, em todas as cultivares, exceto na Carioca. Oliveira (1977) verificou o aparecimento de bandas nas regiões mais anódicas dos géis, em folhas secundárias infectadas da cultivar Cuva $168 \mathrm{~N}$, e atribuiu este fato à necrobiose dos tecidos infectados pelo fungo causador da ferrugem; em tecidos suscetíveis da cultivar Mulatinho, verificou a redução da atividade destas bandas.

Provavelmente esta isoperoxidase é sintetizada em mínimas quantidades, e, com o estímulo de indutores, ou pelo próprio fungo virulento, passa a ser sintetizada de

Tabela 3. Atividade da peroxidase (UE $\mathrm{min}^{-1} \mathrm{mg}^{-1}$ tecido) em quatro cultivares de feijão, no estádio de plântula (V2), três dias após, tratamento com a raça delta de Colletotrichum lindemuthianum (fungo indutor), ácido salicílico e água (controle), e cinco dias após inoculação do patótipo virulento (33/95) de C. lindemuthianum (inóculo desafio) ${ }^{(1)}$.

\begin{tabular}{|c|c|c|c|c|c|c|c|c|}
\hline \multirow[t]{2}{*}{ Tratamento } & \multicolumn{4}{|c|}{ Três dias após indução } & \multicolumn{4}{|c|}{ Cinco dias após inóculo desafio } \\
\hline & AB 136 & Rio Tibagi & Carioca & Macanudo & AB 136 & Rio Tibagi & Carioca & Macanudo \\
\hline Ácido salicílico & $347,0 \mathrm{aA}$ & $281,3 \mathrm{aB}$ & $212,3 \mathrm{aC}$ & $284,3 \mathrm{aB}$ & $395,0 \mathrm{aA}$ & $294,3 \mathrm{aC}$ & $188,0 \mathrm{aD}$ & $301,3 \mathrm{aB}$ \\
\hline C. lindemuthianum & $342,0 \mathrm{bA}$ & $272,0 \mathrm{bB}$ & $206,3 b C$ & $274,0 \mathrm{bB}$ & $386,3 \mathrm{bA}$ & $285,3 b C$ & $176,6 \mathrm{bD}$ & $295,3 \mathrm{bB}$ \\
\hline Controle & $150,3 \mathrm{cA}$ & $112,7 \mathrm{cB}$ & $101,0 \mathrm{cC}$ & $112,0 \mathrm{cB}$ & $170,6 \mathrm{dA}$ & $131,7 \mathrm{~dB}$ & $96,6 \mathrm{dD}$ & $121,3 \mathrm{dC}$ \\
\hline Patótipo virulento(2) & $149,0 \mathrm{cA}$ & $112,3 \mathrm{cB}$ & $101,0 \mathrm{cC}$ & $112,0 \mathrm{cB}$ & $354,0 \mathrm{cA}$ & $238,3 \mathrm{cB}$ & $132,6 \mathrm{cD}$ & $227,0 \mathrm{cC}$ \\
\hline
\end{tabular}

${ }^{(1)}$ Médias seguidas pelas mesmas letras, minúsculas nas colunas e maiúsculas nas linhas, não diferem entre si pelo teste de Duncan a 5\% de probabilidade. ${ }^{(2)}$ Antes da inoculação do patótipo virulento, as médias apresentadas representam tratamento com água. 

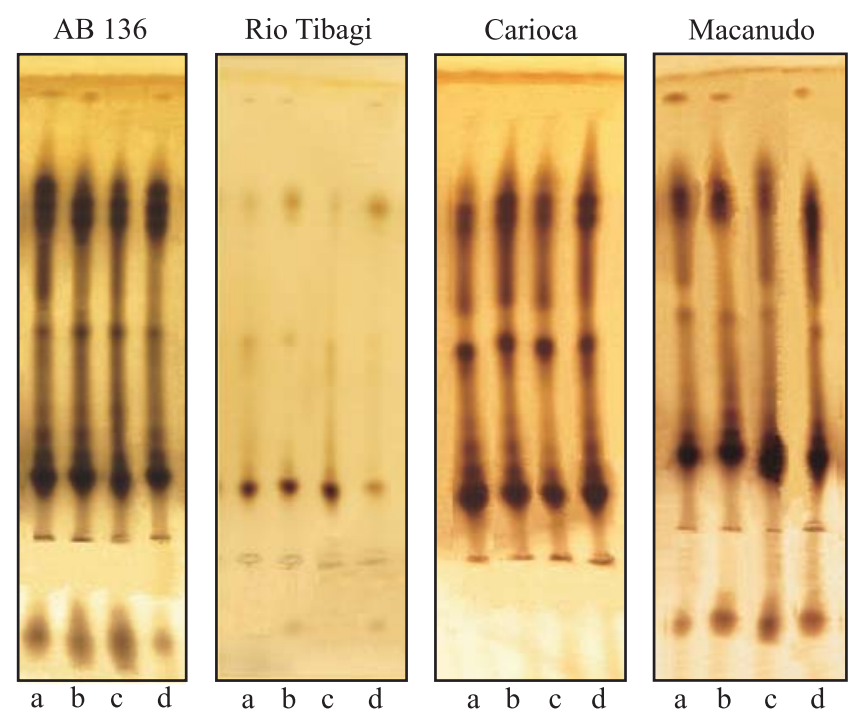

Figura 1. Padrões eletroforéticos de peroxidase (doador de hidrogênio: benzidina), em gel de poliacrilamida, em folhas de quatro cultivares de feijão, obtidos após tratamento de indução com Colletotrichum lindemuthianum (fungo indutor) (a), ácido salicílico (b) e água (c) e inoculação do patótipo virulento de $C$. lindemuthianum (d), com bandas ativas na região anódica dos géis das cultivares AB 136, Rio Tibagi e Macanudo.

novo, nas cultivares que possuem este metabolismo de resistência mais ativo, uma vez que não foi detectada na cultivar Carioca. Resultados semelhantes foram observados quanto ao aparecimento de novas isoenzimas de peroxidase (Birecka et al., 1973; Fleuriet \& Deloire, 1982) e síntese de novo de formas preexistentes após ferimentos (Shannon et al., 1971). Em tomate, uma das isoenzimas de peroxidase, cuja atividade aumenta consideravelmente após um ferimento, está envolvida na possível cura do ferimento no fruto (Fleuriet \& Deloire, 1982). O fato é que tanto o fungo indutor quanto o ácido salicílico induziram a resistência das plantas com respostas semelhantes, indicando assim que, provavelmente, o mesmo metabolismo de indução de resistência possa ocorrer.

\section{Conclusão}

O fungo indutor e o ácido salicílico induzem a resistência das plantas à antracnose, produzindo respostas semelhantes.

\section{Agradecimentos}

À Coordenação do Programa de Pós-Graduação em Ciências Biológicas-Botânica da UFRGS, por possibilitar a realização deste trabalho.

\section{Referências}

AGRIOS, G.N. Plant pathology. San Diego: Academic Press, 1997. $635 \mathrm{p}$.

ASSOCIATION OF OFFICIAL ANALYTICAL CHEMISTS (Gaithersburg, Estados Unidos). Official methods of the Association of Official Analytical Chemists. $11^{\text {th }} \mathrm{ed}$. Washington, 1970. 1015p.

BELL, A.A. Biochemical mechanisms of disease resistance. Annual Review of Plant Physiology, v.32, p.21-81,1981.

BINDSCHEDLER, L.F.; BLEE, K.A.; BUTT, V.S.; DAVIES, D.R.; GARDNER, S.L.; GERRISH, C.; MINIBAYEVA, F. The apoplastic oxidative burst in response to biotic stress in plants: a threecomponent system. Journal of Experimental Botany, v.53, p.13571376, 2002.

BIRECKA, H.; BRIBER, K.A.; CATALFAMO, J.L. Comparative studies on tobacco pith and sweet potato root isoperoxidases in relation to injury, indoleacetic acid, and ethylene effects. Plant Physiology, v.52, p.43-49, 1973.

BIRECKA, H.; GARRAWAY, M.O. Corn leaf isoperoxidase reaction to mechanical injury and infection with Helminthosporium maydis: effects of cycloheximide. Plant Physiology, v.61, p.561- 566, 1978.

CARDOSO, C.O.N.; GARRAWAY, M.O. Bioassay using phenolic compounds and phytoalexins produced in bean plants infected with Fusarium solani f. phaseoli (Burk.) Snyd \& Hans. Summa Phytopathologica, v.3, p.103-116, 1977.

CRUICKSHANK, I.A.M.; PERRIN, D.R. Phytoalexins of the Leguminosae phaseolin from Phaseolus vulgaris L. Life Science, v.2, p.680-682, 1963.

FLEURIET, A.J.J.; DELOIRE, A. Aspects histochimiques et biochimiques de la cicatrisation des fruits de tomate blessés. Phytopathologische Zeitschrift, v.107, p.259-268, 1982.

GASPAR, T.H.; PENEL, C.L.; THORPE, T.; GREPPIN, H. Peroxidases: a survey of their biochemical and physiological roles in higher plants. Genève: Université de Genève, 1982. 324p.

HARTLEB, H.; HEITEFUSS, R.; HOPPE, H. Resistance of crop plants against fungi. Stuttgart: G. Fischer, 1997. 544p.

HYODO, H.; YANG, S.F. Ethylene-enhanced synthesis of phenylalanine ammonia lyase in pea seedlings. Plant Physiology, v.47, p.765-770, 1971.

KAHL, G. Induction and degradation of enzymes in aging plant storage tissue. In: KAHL, G. (Ed.). Biochemistry of wounded plant tissues. Berlin: W. Gruyter, 1978. p.347-390.

KANAZAWA, Y.; SHICHI, H.; URITANI, I. Biosynthesis of peroxidases in sliced or black rot-infected sweet potato roots. 
Agricultural and Biological Chemistry, v.29, p.840-847, 1965.

KAO, C.H. Differential effect of sorbitol and polyethylene glycol on antioxidant enzymes in rice leaves. Plant Growth Regulation, v.39, p.83-89, 2003.

KOSUGE, T. The role of phenolics in host response to infection. Annual Review of Phytopathology, v.7, p.195-222, 1969.

LOWRY, O.H.; ROSEBROUGH, N.R.; FARR, A.L. Protein measurement with the Folin-phenol reagent. Journal of Biological Chemistry, v.10, p.193-265, 1951.

MACHEIX, J.J.; FLEURIET, A.; QUESSADA, M.P. Involvement of phenols and peroxidases in wound healing and grafting. In: GREPPIN, H.; PENEL, C.; GASPAR, T. (Ed.). Molecular and physiological aspects of plant peroxidases. Geneva: University of Geneva, 1986. p.267-286.

MARRIOTT, J.; BEEN, B.O.; PERKINS, C. The aethiology vascular streaking in cassava roots after harvest: association with water loss from wounds. Plant Physiology, v.44, p.38-42, 1978.

MASON, H.S. Comparative biochemistry of the phenolase complex. Advanced in Enzymology and Related Subject of Biochemistry, v.16, p.105-184, 1955.

MATHUR, R.S.; BARNETT, H.L.; LILLY, U.L. Sporulation of Colletotricum lindemuthianum in culture. Phytopathology, v.40, p.104-114, 1950.

MATSUNO, H.; URITANI, I. Physiological behavior of peroxidase isozymes in sweet potato root tissue injured by cutting or with black rot. Plant and Cell Physiology, v.13, p.1091-1101, 1972.

MUELLER, W.C.; BECKMAN, C.H. Ultra structure of the phenol storing cells in roots of banana. Physiological Plant Pathology, v.4, p.187-190, 1974.

NANDAKUMAR, R.; BABU, S.; VISWANATHAN, R.; RAGUCHANDER, T.; SAMIYAPPAN, R. Induction of systemic resistance in rice against sheath blight disease by Pseudomonas fluorescens. Soil Biology and Biochemistry, v.33, p.603-612, 2001.

OLIVEIRA, E.A. Controle genético de isoenzimas de peroxidase e de catecol oxidase em Phaseolus vulgaris $\mathrm{L}$. e suas relações com Uromyces phaseoli (Reb.) Wint. typica Arth. 1977. 151p. Tese (Doutorado) - Universidade Federal do Rio Grande do Sul, Porto Alegre.

OROBER, M.; SIEGRIST, J.; BUCHENAUER, H.; LYR, H.; RUSSEL, P.E.; DEHNE, H.W.; SISLER, H.D. Induction of systemic acquired resistance in cucumber by foliar phosphate aplication. In: INTERNATIONAL REINHARDSBRUNN SYMPOSIUM, 12., 1999, Thuringia. Modern fungicides and antifungal compounds II. Thuringia: International Reinhardsbrunn Symposium, 1999. p.339348.

PADMAJA, G.; BALAGOPAL, C.; POTTY, V.P. Polifenoles y el deterioro fisiologico en yucca. Yuca Boletim Informativo, v.10, p.2-22, 1982.
PIÑOL, M.T.; PALAZÓN, J. Metabolismo secundário. In: BIETOAZCON, J.; TALON, M. Fisiologia y bioquimica vegetal. Madri: McGraw-Hill, 1996. p.273-283.

RAHE, J.E.; KUC, J.; CHUANG, C.M.; WILLIAMS, E.B. Induced resistance in Phaseolus vulgaris to bean anthracnose. Phytopathology, v.59, p.1641-1645, 1969.

SALIN, M.L.; BRIDGES, S.M. Chemiluminescence in soybean root tissue: effect of various substrates and inhibitors. Photobiochemistry and Photobiophysics, v.6, p.57-64, 1983.

SALIN, M.L.; BRIDGES, S.M. Chemiluminescence in wounded root tissue: evidence for peroxidase involvement. Plant Physiology, v.67, p.43-47, 1981.

SCANDALIOS, J.G. Genetic control of multiple molecular forms of enzymes in plants. Review of Biochemical Genetic, v.3, p.32-39, 1969.

SHANNON, L.M.; URITANI, I.; IMASEKI, H. De novo synthesis of peroxidase isozymes in sweet potato slices. Plant Physiology, v.47, p.493-498, 1971.

SLAWINSKA, D. Chemiluminescence and the formation of single oxygen in the oxidation of certain polyphenols and quinones. Photochemistry and Photobiology, v.28, p.453-458, 1978.

SMITH, C.A.; BAILEY, C.H.; HOUGH, L.F. Methods for germinating seeds of some fruit species with special reference to growing seedlings from immature embryos. New Brunswick: The State University of New Jersey, 1963. 62p.

SOUZA, M.V.; TORRES, F.A.G.; RICART, C.A.; FONTES, W.; SANTOS, M.A. Gestão da vida: genoma e pós-genoma. Brasília: UnB, 2001. 143p.

SWAIN, T.; HILLIS, W.C. The phenolic constituents of Prunus domestica. Journal of the Science of Food and Agriculture, v.10, p.63-68, 1959.

WALKER-SIMMONS, M.; HOLLANDER-CZYTKO, H.; ANDERSEN, J.K.; RYAN, C.A. Wound signals in plants: a systemic plant wound signal alters plasm membrane integrity. Proceedings of the National Academy of Sciences, v.81, p.3737-3741, 1984.

WHEATLEY, C. Studies on cassava (Manihot esculenta Crantz) root post-harvest physiological deterioration. 1982.242p. Thesis (Ph.D.) - University of London, London.

ZHENG-CUIMING; TENG-BING; GAO-FENGI; WUZONGPU; ZHENG-CM; TENG-B; GAO-FL; WU-ZP. Studies on the changes of superoxido dismutase, peroxidase and poliphenol oxidase in seed coat of soybeans after infection with soybean mosaic virus. Scientia-Agricultura Sinica, v.32, p.99-101, 1999.

ZONTA, E.P.; MACHADO, A.A. SANEST: sistema de análise estatística para microcomputadores. Pelotas: UFPel, 1984. 48p.

Recebido em 14 de julho de 2003 e aprovado em 18 de fevereiro de 2004 